\title{
Evaluasi Penerapan SIMRS Menggunakan Metode Hot-Fit Di RSUD Dr. Soedirman Kebumen
}

\author{
${ }^{1}$ Prih Diantono Abda'u, ${ }^{2}$ Wing Wahyu Winarno, ${ }^{3}$ Henderi \\ ${ }^{1}$ Politeknik Dharma Patria, ${ }^{2,3}$ Magister Teknik Informatika, Universitas Amikom \\ Yogyakarta \\ ${ }^{1,2,3}$ Yogyakarta, Indonesia \\ E-mail: 19adau88@gmail.com, ${ }^{2}$ wingwahyuwinarno@gmail.com, \\ ${ }^{3}$ henderiugm@gmail.com
}

\begin{abstract}
Abstrak - Evaluasi penerapan Sistem Informasi Manajemen Rumah Sakit (SIMRS) di RSUD Dr. Soedirman Kebumen ini bertujuan untuk mengetahui faktor apakah yang berpengaruh paling besar terhadap keberhasilan SIMRS. Variabel dalam penelitian ini meliputi kualitas sitem, kualitas informasi, kualitas layanan, pengguaan sistem, kepuasan pengguna, struktur organisasi, kondisi fasilitas, dukungan pimpinan, serta manfaat yang diambil dari model HOT-Fit dengan menghilangkan variabel lingkungan organisasi serta menambahkan variabel dukungan pimpinan dan kondisi fasilitas. Dari hasil pembahasan penelitian ini dapat diketahui bahwa keberhasilan penerapan SIMRS di RSUD Dr. Soedirman Kebumen ditentukan oleh aspek Teknologi, Manusia dan Organisasi dapat terlihat bahwa variabel kepuasan pengguna memiliki pengaruh positif terhadap manfaat. Berdasarkan hasil uji t-statistik dengan menggunakan SMARTPLS, kepuasan pengguna merupakan variabel yang memberikan pengaruh paling besar terhadap manfaat yang didapatkan dari SIMRS.
\end{abstract}

\section{Kata Kunci- Hot-Fit, Sistem Informasi, Simrs, Evaluasi}

Abstract - Implementation evaluation of Hospital Management Information System (SIMRS) in RSUD Dr. Soedirman Kebumen aims to determine what factors have the greatest successfulness of SIMRS. The variables in this study are system quality, information quality, service quality, system use, user satisfaction, organization structure, facilitating condition, top mamagement support, and net benefits which adapted from the HOT-Fit model by eliminating the organization environment variable and by added top management support and facilitating condition variables. From this study, we can see that the success of SIMRS implementation in RSUD Dr. Soedirman Kebumen determined by aspects of Technology, Human and Organization can be seen that the user satisfaction variable has a positive influence on the net benefits vatiable. Based on the results of $t$ statistic test by using SMARTPLS software, user satisfaction is the variable that gives the most influence to the net benefits gained from SIMRS.

Keywords-Hot-Fit, Information System, Simrs, Evaluation 
INTENSIF, Vol.2 No.1 February 2018

ISSN: 2580-409X (Print) / 2549-6824 (Online)

http://ojs.unpkediri.ac.id/index.php/intensif

\section{PENDAHULUAN}

SIMRS adalah sistem yang mampu melakukan integrasi dan komunikasi aliran informasi baik di dalam maupun diluar rumah sakit. Sistem informasi ini meliputi: sistem rekam medis elektronik, sistem informasi laboratorium, sistem informasi radiologi (pencitraan medis), sistem informasi farmasi, dan sistem informasi keperawatan. Sistem ini juga memiliki dua fungsi utama yaitu untuk keperluan manajemen dan pengolahan data pasien. Dari sisi manajemen, sistem ini memiliki peranan dalam mengatur data keuangan, material dan teknis, sistem kepegawaian, pembayaran (tagihan) ke pasien, dan perencanaan strategi. Dari sisi pasien berfungsi untuk mengelola data pasien masuk dan pasien keluar serta mengelola data medis pasien yang meliputi perawatan, diagnosis, dan terapi [1]. Evaluasi suatu sistem informasi merupakan usaha nyata untuk mengetahui kondisi sebenarnya suatu penyelenggaraan sistem informasi. Evaluasi sistem informasi adalah suatu kegiatan untuk mengukur atau menggali segala attribute dari sistem (dalam perencanaan, pengembangan, pengimplementasi atau pengoperasian). Evaluasi SIM adalah mendefinisikan seberapa baik SIM dapat beroperasi pada organisasi yang menerapkannya untuk memperbaiki prestasi dimasa mendatang [2]. Evaluasi yang akan dilakukan terkait dengan penerimaan sistem oleh pengguna akhir.

Dalam penelitian ini, peneliti akan melakukan evaluasi penerapan sistem informasi (SIMRS) RSUD Dr. Soedirman Kebumen dengan menggunakan metode HOT-Fit ditinjau dari persepsi pengguna akhir. Dimana, penerapan SIMRS di RSUD Dr. Soedirman Kebumen belum pernah dilakukan evaluasi sehingga pada penelitian ini perluya dilakukan evaluasi penerapan SIMRS di RSUD Dr. Soedirman Kebumen. Metode HOT-Fit merupakan salah satu kerangka teori yang digunakan untuk evaluasi sistem informasi dalam bidang pelayanan kesehatan. Metode HOT-Fit juga ditujukan pada komponen inti dalam sistem informasi yaitu Human (Manusia) - Organization (Organisasi) - Technology (Teknologi) dan kesesuaian hubungan diantara ketiga komponen tersebut [2]. Evaluasi terhadap SIMRS di RSUD Dr. Soedirman Kebumen harus dilakukan karena evaluasi akan menilai, mengukur, memperbaiki atau menyempurnakan sistem informasi manajemen rumah sakit untuk menemukan masalahmasalah potensial yang sedang dihadapi pengguna dan organisasi. Hasil evaluasi dapat digunakan sebagai acuan untuk memperbaiki atau menyempurnakan SIMRS serta mengembangkan potensi yang masih ada, sehingga dapat bermanfaat bagi RSUD Dr. Soedirman Kebumen dalam meningkatkan kinerja dalam pelayanan rumah sakit kearah lebih baik, serta dapat mendukung tujuan, visi dan misi organisasi. Rumusan masalah dari penelitian ini adalah bagaimana cara mengevaluasi SIMRS dengan persepsi pengguna terakhir? 
INTENSIF, Vol.2 No.1 February 2018

ISSN: 2580-409X (Print) / 2549-6824 (Online)

http://ojs.unpkediri.ac.id/index.php/intensif

\section{METODE PENELITIAN}

Penelitian ini menggunakan metode penelitian deskriptif kuantitafif dengan melakukan survei dan mengumpulkan data primer melalui wawancara dengan panduan penyebaran kuisioner terhadap pengguna sistem informasi sebagai responden. Pada penelitian ini yang menjadi objek dan bahan penelitian adalah pengguna Sistem Informasi Manajemen Rumah Sakit (SIMRS) di RSUD Dr. Soedirman Kebumen.

\subsection{Metode Analisis Data}

Penelitian ini menggunakan model Hot-Fit yang dikembangkan oleh Yusof et al, dengan beberapa modifikasi untuk menilai keberhasilan penerapan sistem informasi manajemen kepegawaian. Salah satunya adalah dengan menghilangkan variabel lingkungan organisasi (organization environment). Karena variabel tersebut dinilai terlalu luas sehingga peneliti mengganti variabel lingkungan organisasi dengan kondisi fasilitas (facilitating condition) dan dukungan pimpinan (top management support).

Tabel 1. VARIABEL INDIKATOR MODEL HOT-FIT

\begin{tabular}{|c|c|c|}
\hline Variabel Laten & Indikator variable & Kode \\
\hline \multirow{5}{*}{$\begin{array}{c}\text { Kualitas Sistem } \\
\text { (Sistem Quality) } \\
\text { (KS) }\end{array}$} & SIMRS mudah untuk digunakan dan user frendly & KS1 \\
\hline & $\begin{array}{c}\text { Tampilan SIMRS sangat sederhana sehingga tidak } \\
\text { membingungkan }\end{array}$ & KS2 \\
\hline & $\begin{array}{l}\text { SIMRS memiliki hak akses sehingga kerahasian data } \\
\text { terjamin }\end{array}$ & KS3 \\
\hline & SIMRS mudah diakses & KS4 \\
\hline & SIMRS jarang mengalami error & KS5 \\
\hline \multirow{5}{*}{$\begin{array}{l}\text { Kualitas } \\
\text { Informasi } \\
\text { (Information } \\
\text { Quality) (KI) }\end{array}$} & $\begin{array}{c}\text { Informasi yang dihasilkan SIMRS sesuai dengan data yang } \\
\text { diinputkan }\end{array}$ & KI1 \\
\hline & Informasi yang dihasilkan SIMRS sesuai dengan kenyataan & KI2 \\
\hline & Informasi yang dihasilkan SIMRS tepat dan akurat & KI3 \\
\hline & Informasi yang dihasilkan SIMRS sangat lengkap dan detail & KI4 \\
\hline & Informasi yang dihasilkan SIMRS mudah untuk dibaca & KI5 \\
\hline \multirow{3}{*}{$\begin{array}{l}\text { Kualitas Layanan } \\
\text { (Service Quality) } \\
\text { (KL) }\end{array}$} & Adanya panduan penggunaan SIMRS & KL1 \\
\hline & $\begin{array}{l}\text { Layanan yang cepat dan responsif dari pihak pengembang } \\
\text { SIMRS }\end{array}$ & KL2 \\
\hline & SIMRS dapat diakses dari manapun & KL3 \\
\hline \multirow{5}{*}{$\begin{array}{l}\text { Penggunaan } \\
\text { Sistem (Sistem } \\
\text { Use) (PS) }\end{array}$} & $\begin{array}{l}\text { Penggunaan SIMRS mempermudah proses pencarian } \\
\text { informasi }\end{array}$ & PS1 \\
\hline & Penggunaan SIMRS membantu pekerjaan sehari-hari saya & PS2 \\
\hline & $\begin{array}{l}\text { Penggunaan SIMRS dapat membantu dalam pengambilan } \\
\text { keputusan }\end{array}$ & PS3 \\
\hline & $\begin{array}{l}\text { Saya memiliki ketrampilan yang baik dalam menggunakan } \\
\text { SIMRS }\end{array}$ & PS4 \\
\hline & Semua pekerjaan saya sangat tergantung pada SIMRS & PS5 \\
\hline
\end{tabular}


INTENSIF, Vol.2 No.1 February 2018

ISSN: 2580-409X (Print) / 2549-6824 (Online)

http://ojs.unpkediri.ac.id/index.php/intensif

Tabel 2. VARIABEL INDIKATOR MODEL HOT-FIT [LANJUTAN]

\begin{tabular}{|c|c|c|}
\hline Variabel Laten & Indikator variable & Kode \\
\hline \multirow{6}{*}{$\begin{array}{l}\text { Kepuasan } \\
\text { Pengguna } \\
\quad(\text { User } \\
\text { Satisfaction) }(\mathrm{KP})\end{array}$} & $\begin{array}{l}\text { Fasilitas dan fitur-fitur yang ada pada SIMRS sudah sesuai } \\
\text { dengan kebutuhan }\end{array}$ & KP1 \\
\hline & Saya puas atas penggunaan SIMRS & KP2 \\
\hline & $\begin{array}{c}\text { Semua fitur dan fungsi yang ada pada SIMRS telah berjalan } \\
\text { sesuai dengan kebutuhan }\end{array}$ & KP3 \\
\hline & Saya puas terhadap tampilan dari SIMRS & KP4 \\
\hline & $\begin{array}{l}\text { Secara keseluruhan SIMRS sudah sesuai dengan harapan } \\
\text { anda dalam membantu tugas sehari-hari anda }\end{array}$ & KP5 \\
\hline & SIMRS mudah untuk digunakan & KP6 \\
\hline \multirow{5}{*}{$\begin{array}{c}\text { Struktur } \\
\text { Organisasi } \\
\text { ( Organization } \\
\text { Structure ) (SO) }\end{array}$} & $\begin{array}{c}\text { SIMRS diterapkan sebagai strategi untuk peningkatan } \\
\text { kinerja }\end{array}$ & SO1 \\
\hline & $\begin{array}{c}\text { SIMRS dapat digunakan sesuai dengan fungsi dan tugas } \\
\text { dalam organisasi }\end{array}$ & $\mathrm{SO} 2$ \\
\hline & SIMRS dapat membantu koordinasi antar unit dengan baik & $\mathrm{SO} 3$ \\
\hline & $\begin{array}{l}\text { Implementasi SIMRS telah direncanakan dengan baik oleh } \\
\text { pihak manajemen }\end{array}$ & $\mathrm{SO} 4$ \\
\hline & $\begin{array}{l}\text { Pihak manajemen menyediakan dukungan fasilitas } \\
\text { infrastrukur untuk mendukung implementasi SIMRS }\end{array}$ & SO5 \\
\hline \multirow{3}{*}{$\begin{array}{l}\text { Kondisi Fasilitas } \\
\quad \text { (Facilitating } \\
\text { Condition) }(\mathrm{KF})\end{array}$} & $\begin{array}{c}\text { Instansi menyediakan sumber daya, sarana dan prasarana } \\
\text { (hardware, software, infrastruktur jaringan, pemeliharaan } \\
\text { dan dukungan teknis) yang mendukung penggunaan } \\
\text { SIMRS }\end{array}$ & KF01 \\
\hline & Instansi menyediakan pelatihan menggunakan SIMRS & KF02 \\
\hline & $\begin{array}{c}\text { Terdapat petugas yang bertanggung jawab dan memberikan } \\
\text { bantuan jika terjadi masalah dengan SIMRS }\end{array}$ & KF03 \\
\hline \multirow{3}{*}{$\begin{array}{l}\text { Dukungan } \\
\text { Pimpinan }(\text { Top } \\
\text { Management } \\
\text { Support) (DP) }\end{array}$} & Implementasi SIMRS didukung pimpinan/ top management & DP01 \\
\hline & Atasan menganjurkan menggunakan SIMRS & $\mathrm{DP} 02$ \\
\hline & Atasan menganggap SIMRS penting dan bermanfaat & DP03 \\
\hline \multirow{6}{*}{ Net Benefit (NB) } & SIMRS membantu tugas pekerjaan sehari-hari & NB1 \\
\hline & SIMRS dapat meningkatkan efisiensi pekerjaan & NB2 \\
\hline & SIMRS membantu pencapaian tujuan dengan efektif & NB3 \\
\hline & $\begin{array}{c}\text { SIMRS dapat meningkatkan komunikasi antar seluruh } \\
\text { bagian dalam organisasi }\end{array}$ & NB4 \\
\hline & $\begin{array}{l}\text { SIMRS dapat meningkatkan kinerja organisasi dalam } \\
\text { menghadapi persaingan yang ada saat ini }\end{array}$ & NB5 \\
\hline & SIMRS dapat mendukung visi dan misi dari organisasi & NB6 \\
\hline
\end{tabular}

\subsection{5. Pemodelan Inner Model dan Outer Model}

Inner model merupakan model structural yang menghubungkan antara variabel laten dengan variabel laten lainnya. Inner model penelitian ini dapat digambarkan sebagai berikut : 
INTENSIF, Vol.2 No.1 February 2018

ISSN: 2580-409X (Print) / 2549-6824 (Online)

http://ojs.unpkediri.ac.id/index.php/intensif

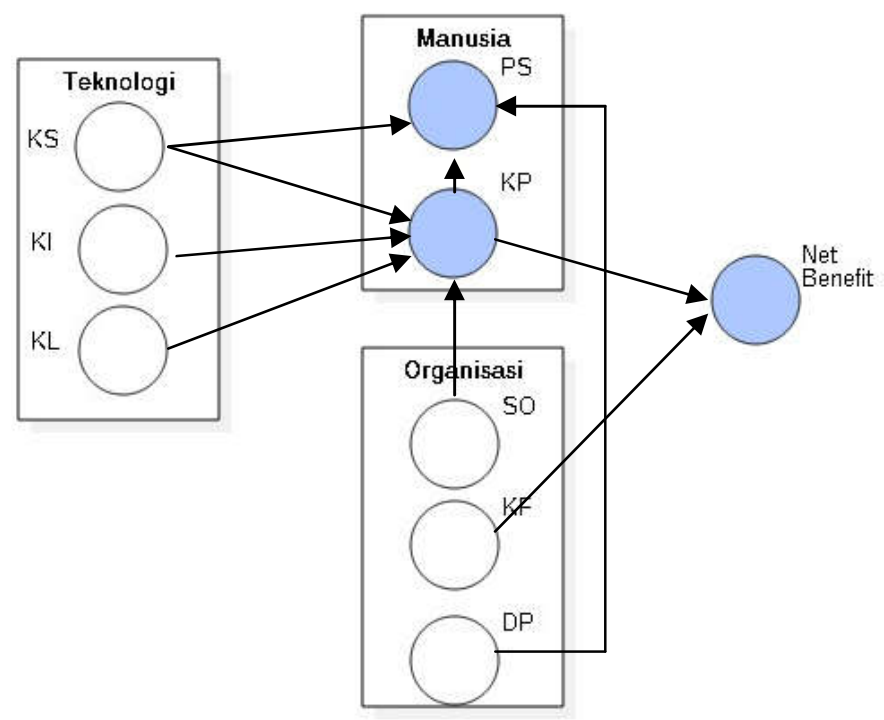

Gambar 2. INNER MODEL

Keterangan

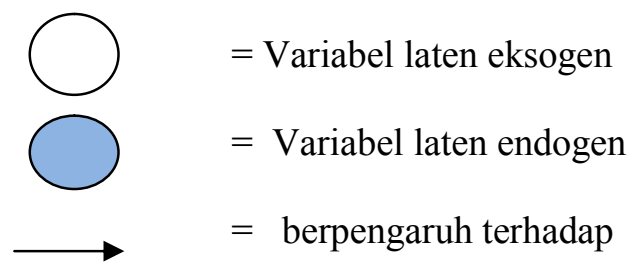

Dari gambar 2 telah ditentukan bahwa terdapat tiga variabel endogen yaitu Penggunaan Sistem (PS), Kepuasaan Pengguna (KP) serta Net Benefit (NB) yang dipengaruhi oleh enam variabel eksogen yaitu Kualitas Sistem (KS), Kualitas Informasi (KI), Kualitas Layanan (KL), Struktur Organisai (SO), Kondisi Fasilitas (KF) serta Dukungan Pimpinan (DP). Outer model merupakan model pengukuran yang menghubungkan variabel indikator dengan variabel latennya. Model pengukuran (outer model) digunakan untuk menilai validitas dan realibilitas model. Uji validitas dilakukan untuk mengetahui kemampuan instrumen penelitian mengukur apa yang seharusnya diukur [3]. Sedangkan untuk uji realibilitas bertujuan untuk mengukur konsistensi alat ukur dalam mengukur suatu konsep atau dapat juga digunakan untuk mengukur konsistensi responden dalam menjawab item pernyataan dalam kuesioner atau instrumen penelitian. 
INTENSIF, Vol.2 No.1 February 2018

ISSN: 2580-409X (Print) / 2549-6824 (Online)

http://ojs.unpkediri.ac.id/index.php/intensif

\section{HASIL DAN PEMBAHASAN}

\subsection{Pengujian Validitas}

Pengujian validitas digunakan untuk menguji kemampuan (keakuratan) suatu indikator sehingga dapat mewakili suatu variabel laten. Dalam partial least square, untuk menguji validitas dilakukan dengan melakukan pengukuran Convergent validity dan discriminant validity evaluasi terhadap outer model (measurement outer model). Ukuran convergent validity dikatakan tinggi jika nilai loading factor $(\lambda)$ lebih dari 0.7 , namun nilai loading 0.5 sampai 0.6 dianggap cukup [3]. Discrimant validity dinilai berdasarkan crossloading pengukuran dengan konstruks, jika korelasi konstruk dengan item pengukuran lebih besar daripada ukuran konstruk lainnya, maka hal ini menunjukkan konstruk laten memprediksi ukuran pada blok mereka lebih baik dari ukuran pada blok lainnya [4].

Tabel 2. HASIL AKHIR UJI VALIDITAS

\begin{tabular}{|c|c|c|c|}
\hline Variabel Laten & $\begin{array}{c}\text { Indikator } \\
\text { Variabel }\end{array}$ & $\begin{array}{c}\text { Nilai } \\
\text { Loading }\end{array}$ & Keterangan \\
\hline \multirow{5}{*}{$\begin{array}{c}\text { Kualitas Sistem (System } \\
\text { Quality) (KS) }\end{array}$} & KS1 & 0,632 & Valid \\
\hline & KS2 & 0,681 & Valid \\
\hline & $\mathrm{KS} 3$ & 0,804 & Valid \\
\hline & KS4 & 0,636 & Valid \\
\hline & KS5 & 0,719 & Valid \\
\hline \multirow{5}{*}{$\begin{array}{c}\text { Kualitas Informasi } \\
\text { (Information Quality) (KI) }\end{array}$} & KI1 & 0,804 & Valid \\
\hline & KI2 & 0,800 & Valid \\
\hline & KI3 & 0,865 & Valid \\
\hline & KI4 & 0,773 & Valid \\
\hline & KI5 & 0,728 & Valid \\
\hline \multirow{3}{*}{$\begin{array}{c}\text { Kualitas Layanan (Service } \\
\text { Quality) }(\mathrm{KL})\end{array}$} & KL1 & 0,643 & Valid \\
\hline & KL2 & 0,840 & Valid \\
\hline & KL3 & 0,837 & Valid \\
\hline \multirow{3}{*}{ Penggunaan Sistem (PS) } & PS1 & 0,894 & Valid \\
\hline & PS2 & 0,876 & Valid \\
\hline & PS3 & 0,779 & Valid \\
\hline \multirow{6}{*}{$\begin{array}{c}\text { Kepuasan Pengguna } \\
\text { (KP) }\end{array}$} & KP1 & 0,824 & Valid \\
\hline & KP2 & 0,842 & Valid \\
\hline & KP3 & 0,768 & Valid \\
\hline & KP4 & 0,755 & Valid \\
\hline & KP5 & 0,848 & Valid \\
\hline & KP6 & 0,642 & Valid \\
\hline \multirow{4}{*}{$\begin{array}{l}\text { Struktur Organisasi } \\
\text { (SO) }\end{array}$} & SO1 & 0,725 & Valid \\
\hline & $\mathrm{SO} 2$ & 0,672 & Valid \\
\hline & SO4 & 0,683 & Valid \\
\hline & SO5 & 0,774 & Valid \\
\hline
\end{tabular}


INTENSIF, Vol.2 No.1 February 2018

ISSN: 2580-409X (Print) / 2549-6824 (Online)

http://ojs.unpkediri.ac.id/index.php/intensif

Tabel 2. HASIL AKHIR UJI VALIDITAS [LANJUTAN]

\begin{tabular}{cccc}
\hline \hline Variabel Laten & $\begin{array}{c}\text { Indikator } \\
\text { Variabel }\end{array}$ & $\begin{array}{c}\text { Nilai } \\
\text { Loading }\end{array}$ & Keterangan \\
& KF1 & 0,775 & Valid \\
\cline { 2 - 4 } Kondisi Fasilitas (KF) & KF2 & 0,764 & Valid \\
\cline { 2 - 4 } & KF3 & 0,807 & Valid \\
\hline \multirow{3}{*}{ Dukungan Pimpinan (DP) } & DP1 & 0,877 & Valid \\
\cline { 2 - 4 } & DP2 & 0,942 & Valid \\
\cline { 2 - 4 } & DP3 & 0,902 & Valid \\
\hline \multirow{3}{*}{ Net Benefit (NB) } & NB1 & 0,710 & Valid \\
\cline { 2 - 4 } & NB2 & 0,819 & Valid \\
\cline { 2 - 4 } & NB3 & 0,816 & Valid \\
\cline { 2 - 4 } & NB4 & 0,798 & Valid \\
\cline { 2 - 4 } & NB5 & 0,804 & Valid \\
\cline { 2 - 4 } & NB6 & 0,622 & Valid \\
\hline
\end{tabular}

\subsection{Pengujian Reliabilitas}

Pengujian realibilitas variabel dapat diukur dengan dua kriteria yaitu composite reability dan cronbach alpha. Variabel dikatakan realibel jika nilai composite reability dan cronbach alpha jika memiliki nilai di atas 0.7 [4]. Hasil uji realibilitas, dapat terlihat pada tabel 3 di bawah ini

Tabel 3. UJI RELIABILITAS

\begin{tabular}{lcc}
\hline \hline \multicolumn{1}{c}{ Variabel } & $\begin{array}{c}\text { Cronbach's } \\
\text { Alpha }\end{array}$ & $\begin{array}{c}\text { Composite } \\
\text { Reliability }\end{array}$ \\
\hline Dukungan Pimpinan & 0.893 & 0.933 \\
\hline Kepuasan Pengguna & 0.871 & 0.904 \\
\hline Kondisi Fasilitas & 0.702 & 0.826 \\
\hline Kualitas Informasi & 0.854 & 0.896 \\
\hline Kualitas Layanan & $\mathbf{0 . 6 9 3}$ & 0.820 \\
\hline Kualitas Sistem & 0.739 & 0.825 \\
\hline Net Benefit & 0.862 & 0.897 \\
\hline Penggunaan Sistem & 0.830 & 0.899 \\
\hline Struktur Organisasi & 0.711 & 0.817 \\
\hline
\end{tabular}

Berdasarkan Tabel 3 terlihat bahwa variabel laten Kualitas Layanan tidak reliabel karena memiliki nilai dibawah 0.7 .

\subsection{Pengujian Inner Model}

Inner model kadang disebut juga sebagai structural model yang menggambarkan hubungan antara variabel laten. Inner model dievaluasi dengan menggunakan nilai R-Square yang 
INTENSIF, Vol.2 No.1 February 2018

ISSN: 2580-409X (Print) / 2549-6824 (Online)

http://ojs.unpkediri.ac.id/index.php/intensif

merupakan uji goodness-fit variabel dependen untuk menunjukkan koefisien determinasi, nilai R-square sebesar $0.67,0.33$ dan 0.19 variabel laten endogen dalam model struktural mengindikasikan bahwa model "baik","moderat" dan "lemah" [4].

Tabel 4. Nilai R-SQUARE

\begin{tabular}{cc}
\hline \hline Variabel & R Square \\
\hline $\mathrm{KP}$ & 0.658 \\
\hline $\mathrm{NB}$ & 0.461 \\
\hline $\mathrm{PS}$ & 0.350 \\
\hline
\end{tabular}

Nilai R-Square KP 0.658, hal ini berarti bahwa variabel dependen KP dapat dijelaskan oleh variabel independen KI, KL, KS dan SO sebesar 65,8\% atau memiliki pengaruh "moderat" sedangkan 34,2\% dijelaskan variabel lain diluar yang diteliti. Nilai R-Square PS 0.35 hal ini berarti variabel dependen PS dapat dijelaskan oleh variabel independen KS, DP dan KP sebesar $35 \%$ atau memiliki pengaruh "moderat" sedangkan 65\% dijelaskan variabel lain diluar penelitian ini. Nilai R-square variabel dependen NB sebesar 0.461 hal ini berarti variabel PS dapat dijelaskan oleh variabel KP dan KF sebesar $46 \%$ atau memiliki pengaruh "moderat" sedangkan 54\% dijelaskan oleh variabel lain diluar penelitian ini.

\subsection{Uji Hipotesis}

Uji Hipotesis dilakukan dengan uji t-statistik, untuk menguji hubungan apakah variabelvariabel independen secara parsial berpengaruh nyata atau tidak terhadap variabel dependen. pengujian hipotesis tingkat signifikansi yang digunakan adalah $95 \%(\alpha=0.05)$. Nilai $\mathrm{t}$ tabel dengan tingkat signifikansi 95\% adalah 1,96. Ukuran signifikansi keterdukungan hipotesis dapat digunakan perbandingan nilai $\mathrm{T}$-table dan $\mathrm{T}$-statistic. Jika $\mathrm{T}$-statistic lebih tinggi dibandingkan nilai T-table, berarti hipotesis terdukung atau diterima. Pada SmartPLS untuk memperoleh hasil uji hipotesis dilakukan dengan bootsrapping [4] Berikut ini adalah hasil uji tstatistik dapat dilihat pada Tabel 5.

Tabel 5. HASIL UjI T-STATISTIK

\begin{tabular}{lcccc}
\hline \hline Hipotesis & $\begin{array}{c}\text { Original } \\
\text { Sample (O) }\end{array}$ & $\begin{array}{c}\text { Sample } \\
\text { Mean (M) }\end{array}$ & $\begin{array}{c}\text { Standard Deviation } \\
\text { (STDEV) }\end{array}$ & $\begin{array}{c}\text { T Statistics } \\
(|\mathbf{O} / \mathbf{S T D E V}|)\end{array}$ \\
\hline KS -> PS & 0.371 & 0.372 & 0.141 & 2.634 \\
\hline KS -> KP & 0.392 & 0.376 & 0.097 & 4.053 \\
\hline KI -> KP & 0.200 & 0.203 & 0.145 & 1.381 \\
\hline KL -> KP & 0.241 & 0.247 & 0.102 & 2.361 \\
\hline
\end{tabular}


INTENSIF, Vol.2 No.1 February 2018

ISSN: 2580-409X (Print) / 2549-6824 (Online)

http://ojs.unpkediri.ac.id/index.php/intensif

Tabel 5. HASIL UJi T-STATISTIK [LANJUTAN]

\begin{tabular}{lcccc}
\hline \hline Hipotesis & $\begin{array}{c}\text { Original } \\
\text { Sample (O) }\end{array}$ & $\begin{array}{c}\text { Sample } \\
\text { Mean (M) }\end{array}$ & $\begin{array}{c}\text { Standard Deviation } \\
\text { (STDEV) }\end{array}$ & $\begin{array}{c}\text { T Statistics } \\
(|\mathbf{O} / \mathbf{S T D E V}|)\end{array}$ \\
\hline KP -> PS & 0.068 & 0.069 & 0.160 & 0.422 \\
\hline SO -> KP & 0.188 & 0.208 & 0.127 & 1.484 \\
\hline KP -> NB & 0.624 & 0.612 & 0.142 & 4.392 \\
\hline KF -> NB & 0.090 & 0.131 & 0.144 & 0.623 \\
\hline DP -> PS & 0.244 & 0.253 & 0.137 & 1.786 \\
\hline
\end{tabular}

Berdasarkan hasil uji t-statistik, maka hasil uji hipotesis dapat dijelaskan seperti pada Gambar 3

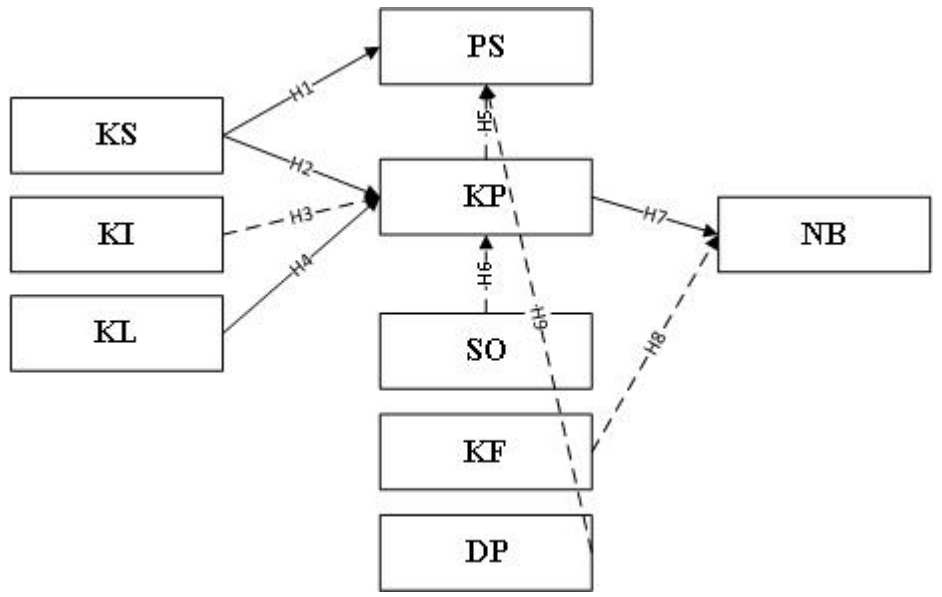

Gambar 3. HASIL UJI HIPOTESIS

Keterangan:

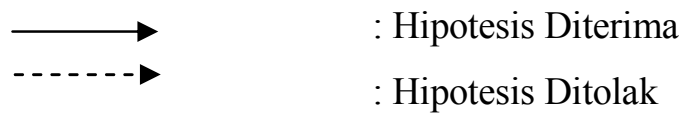

Berdasarkan Gambar 3 maka dapat dijelaskan hasil uji hipotesis dalam penelitian ini :

H1 : Hasil t-statistik KS->PS memiliki nilai t hitung sebesar 2,63 menunjukkan bahwa nilai $\mathrm{t}$ hitung lebih besar dari $\mathrm{t}$ tabel sebesar 1,96 berarti $\mathrm{H} 1$ diterima atau terdapat hubungan yang searah (positif) antara kualitas sistem (KS) terhadap penggunaan sistem (PS)

H2 : Hasil t-statistik KS->KP memiliki nilai $t$ hitung sebesar 4,05 menunjukkan bahwa nilai $\mathrm{t}$ hitung lebih besar dari nilai t tabel sebesar 1,96 berarti $\mathrm{H} 2$ diterima atau terdapat hubungan yang searah (positif) antara kualitas sistem (KS) terhadap kepuasan pengguna (KP). 
INTENSIF, Vol.2 No.1 February 2018 ISSN: 2580-409X (Print) / 2549-6824 (Online) http://ojs.unpkediri.ac.id/index.php/intensif

H3 : Hasil t-statistik KI->KP memiliki nilai sebesar 1,38 menunjukkan bahwa nilai t hitung lebih kecil dari nilai $\mathrm{t}$ tabel sebesar 1,96 berarti $\mathrm{H} 3$ ditolak atau terdapat hubungan tidak searah (negatif) antara kualitas informasi terhadap kepuasan pengguna.

H4 : Hasil t-statistik KL->KP memiliki nilai sebesar 2,36 nilai $\mathrm{t}$ hitung lebih besar dari nilai $\mathrm{t}$ tabel sebesar 1,96 berarti H4 diterima atau terdapat hubungan yang searah (positif) antara kualitas layanan dan kepuasan pengguna.

H5 : Hasil t-statistik KP->PS memiliki nilai sebesar 0,42 nilai t hitung lebih kecil dari nilai tabel sebesar 1,96 berarti H5 diolak atau terdapat hubungan tidak searah (negatif) antara kepuasan pengguna terhadap penggunaan sistem.

H6 : Hasil t-statistik SO->KP memiliki nilai sebesar 1,48 nilai $\mathrm{t}$ hitung lebih kecil dari nilai $\mathrm{t}$ tabel sebesar 1,96 berarti H6 ditolak atau terdapat hubungan tidak searah (negatif) antara sistem operasi terhadap kepuasan pengguna.

H7 : Hasil t-statistik KP->NB memiliki nilai sebesar 4,39 nilai t hitung lebih besar dari nilai t tabel sebesar 1,96 berarti $\mathrm{H} 7$ diterima atau terdapat hubungan searah (positif) antara kepuasan pengguna terhadap net benefit.

H8 : Hasil t-statistik KF->NB memiliki nilai sebesar 0,62 nilai $\mathrm{t}$ hitung lebih kecil dari nilai $\mathrm{t}$ tabel sebesar 1,96 berarti $\mathrm{H} 8$ ditolak atau terdapat hubungan tidak searah (negatif) antara kondisi fasilitas terhadap net benefit.

H9 : Hasil t-statistik DP->PS memiliki nilai sebesar 1,78 nilai t hitung lebih kecil dari t tabel sebesar 1,96 berarti $\mathrm{H} 9$ ditolak atau terdapat hubungan tidak searah (negatif) antara dukungan pimpinan terhadap penggunaan sistem.

\section{KESIMPULAN DAN SARAN}

Berdasarkan dari hasil analisis data statistik dan pembahasan mengenai evaluasi SIMRS di RSUD Dr. Soedirman Kebumen dapat diambil kesimpulan yaitu: (1) Kesuksesan dalam penerapan SIMRS RSUD Dr. Soedirman Kebumen dipengaruhi oleh faktor kualitas sistem, kualitas layanan, penggunaan sistem, kepuasan pengguna dan manfaat. Kepuasan pengguna merupakan variabel yang memberikan pengaruh paling besar. (2) Manfaat dipengaruhi secara langsung oleh kepuasan pengguna, hal ini berarti semakin tinggi manfaat yang dirasakan oleh pengguna dalam menggunakan SIMRS maka semakin tinggi juga kepuasan pengguna 
INTENSIF, Vol.2 No.1 February 2018

ISSN: 2580-409X (Print) / 2549-6824 (Online)

http://ojs.unpkediri.ac.id/index.php/intensif

dalam menggunakan SIMRS. (3) Adanya faktor-faktor yang belum berpengaruh seperti kualitas informasi, struktur organisasi, kondisi fasilitas, dan dukungan pemimpin. Berdasarkan hasil penelitian dan kesimpulan penelitian yang telah diuraikan sebelumnya, maka dapat disampaikan saran sebagai berikut: (1) Indikator atau butir pertanyaan pada masing-masing variabel agar disusun dengan bahasa yang lebih detail dan merujuk pada masalah apa saja yang ingin diselesaikan. (2) Perlunya penelitian lebih lanjut mengenai faktor-faktor lain yang mempengaruhi SIMRS dalam meningkatkan kualitas sebuah sistem informasi. (3) Untuk penelitian selanjutnya diharapkan dapat meminimalisir kelemahan dalam penelitian ini seperti misal penelitian ini hanya berdasar pada persepsi dari pengguna SIMRS. Serta disarankan untuk mencoba menambahkan variabel-variabel yang lainnya atau bahkan mengurangi beberapa variabel yang dianggap tidak memberikan pengaruh pada penelitian ini.

\section{DAFTAR PUSTAKA}

[1] Kusumadewi, Sri. "Aplikasi informatika medis untuk penatalaksanaan diabetes melitus secara terpadu." Seminar Nasional Aplikasi Teknologi Informasi. 2009.

[2] Jalaludin, Asep. Modul Sistem Infomasi Manajemen, SIM-sevz@2007

[3] Jogiyanto, H. M., and Willy Abdillah. "Konsep dan aplikasi PLS (Partial Least Square) untuk penelitian empiris." BPFE Fakultas Ekonomika dan Bisnis UGM. Yogyakarta (2009).

[4] Ghozali, Imam. "Analisis Multivariat Dengan Menggunakan SPSS." Edisi Tiga. Semarang. Badan Penerbit Universitas Diponegoro (2011). 